(6) OPEN ACCESS

\title{
Harmonising summary measures of population health using global survey instruments
}

\author{
Nicolas Berger, ${ }^{1,2}$ Jean-Marie Robine, ${ }^{3,4}$ Toshiyuki Ojima, ${ }^{5}$ Jennifer Madans, ${ }^{6}$ \\ Herman Van Oyen ${ }^{1}$
}

- Additional material is published online only. To view please visit the journal online (http://dx.doi.org/10.1136/jech2015-206870).

${ }^{1}$ Public Health and Surveillance, Scientific Institute of Public Health, Brussels, Belgium

${ }^{2}$ Faculty of Public Health \& Policy, London School of Hygiene \& Tropical Medicine, London, UK

${ }^{3}$ French Institute of Health and Medical Research (INSERM)

Montpellier, France

${ }^{4}$ École Pratique des Hautes Études, Paris, France

${ }^{5}$ Hamamatsu University School of Medicine, Hamamatsu, Japan

${ }^{6}$ National Center for Health Statistics, Washington, USA

\section{Correspondence to} Nicolas Berger, Faculty of Public Health \& Policy, London School of Hygiene \& Tropical Medicine, 15-17 Tavistock Place, London WC1H 9SH, UK; nicolas.berger@Ishtm.ac.uk

Received 23 October 2015 Revised 2 April 2016 Accepted 13 April 2016 Published Online First 10 May 2016

CrossMark

To cite: Berger $\mathrm{N}$

Robine J-M, Ojima T, et al. J

Epidemiol Community Health 2016:70:1039-1044.

\section{ABSTRACT}

Summary measures of population health—health expectancies in particular-have become a standard for quantifying and monitoring population health. To date, cross-national comparability of health expectancies is limited, except within the European Union (EU). To advance international comparability, the European Joint Action on Healthy Life Years (JA: EHLEIS) set up an international working group. The working group discussed the conceptual basis of summary measures of population health and made suggestions for the development of comparable health expectancies to be used across the EU and Organisation for Economic Co-operation and Development (OECD) members. In this paper, which summarises the main results, we argue that harmonised health data needed for health expectancy calculation can best be obtained from 'global' survey measures, which provide a snapshot of the health situation using 1 or a few survey questions. We claim that 2 global measures of health should be pursued for their high policy relevance: a global measure of participation restriction and a global measure of functional limitation. We finally provide a blueprint for the future development and implementation of the 2 global measures. The blueprint sets the basis for subsequent international collaboration, having as a core group Member States of the EU, the USA and Japan. Other countries, in particular OECD members, are invited to join the initiative.

\section{BACKGROUND}

Summary measures of population health-health expectancies in particular-have become a standard for quantifying and monitoring population health. ${ }^{1}{ }^{2}$ Health expectancies indicate the number of remaining years that a person is expected to live in a health state such as in good (bad) perceived health, with(out) disability or with(out) chronic diseases. The indicators were developed to address whether or not longer life is being accompanied by an increase in the time lived in good or in bad health, adding a dimension of quality to the quantity of life lived. ${ }^{3}$ Health expectancies provide useful information for health, disability, ageing and social policies. They are also valuable to compare countries with each other not only to create rankings, but to learn from countries' experiences. Such comparisons are effective providing that the data used-especially the health data-are equivalent across countries.

To date, cross-national comparability of health expectancies is limited, except within the European Union (EU). Since 2005, three harmonised health expectancies have been annually monitored in the
EU: life expectancy without activity limitationalso known as Healthy Life Years-life expectancy in good self-rated health and life expectancy without chronic morbidity. Each indicator is based on one of the three global survey questions forming the Minimum European Health Module (MEHM). ${ }^{4}$ Outside the EU, health expectancies often target analogous health dimensions but rely on different measures, as it is the case in the USA. ${ }^{5}$ It therefore appears that international comparability could be better achieved based on clear conceptual specification of the health dimensions targeted and the use of measurement guidelines. ${ }^{6}$

To advance international comparability, the European Joint Action on Healthy Life Years (JA: EHLEIS, http://www.eurohex.eu) set up a working group composed of experts from the EU, Japan, the USA, the Organisation for Economic Co-operation and Development (OECD) and the WHO. During three seminars held in Paris between 2012 and 2014, the working group discussed the conceptual basis of summary measures of population health and made suggestions for the development of comparable health expectancies to be used across the EU and OECD members (see online supplementary file for more details on the working group seminars and methods). ${ }^{7} 8$ This paper presents the main results from the working group: it sketches a blueprint for the future development and implementation of two global measures of population health to be used to calculate comparable health expectancies.

\section{USING GLOBAL SURVEY MEASURES TO EASE HEALTH MONITORING}

National agencies are often reluctant to introduce lengthy survey instruments into their monitoring systems, invoking space restrictions and unwillingness to break existing time series by the replacement of existing instruments. This priority given to national interests may well contribute to explaining why cross-national comparisons of health data are still limited despite international harmonisation efforts.

To overcome the difficulty, global health measures have been proposed as a pragmatic solution for collecting comparable health data. Global health measures, sometimes called 'general' measures, provide a snapshot of the health situation using one or a few survey questions. ${ }^{4} 9$ They are designed to require little room and time, which makes their inclusion in various health and nonhealth surveys easier and, therefore, facilitates frequent measurement and better monitoring over time. Recent experience with the MEHM has 
Table 1 Technical constraints for global health instruments

\begin{tabular}{ll}
\hline Constraint & Description \\
\hline Conciseness & $\begin{array}{l}\text { A global health instrument must be concise and is obtained from one question or a restricted number of questions (eg, branch-and-stem } \\
\text { format, several items combined). Conciseness should be evaluated in terms of survey time required to answer the question(s). } \\
\text { A global health instrument has to be easily grasped by respondents. The cognitive burden on the respondent should be as low as } \\
\text { possible. The grammar and concepts used in the language of reference (ie, English) should have equivalents in other target languages. } \\
\text { The simplicity (or complexity) of a question is best assessed qualitatively using cognitive and field tests. It can also be evaluated during } \\
\text { the design phase using the best practice of questionnaire design. Simplicity can be assessed using: the number of clauses, the number of } \\
\text { words per clause, the inclusion of low frequency words (ie, words which are not often used in everyday life language, such as }\end{array}$ \\
'participation'), the presence of vague or imprecise relative terms (eg, 'seldom'), the presence of vague or ambiguous noun phrases (such \\
as abstract nouns which have unclear or ambiguous referent), or the syntax. \\
A global health instrument should be relevant to the adult population targeted in surveys, often individuals aged 15 years or older. \\
$\begin{array}{l}\text { Usability for general population } \\
\text { surveys } \\
\text { Amenability to multi-modes of } \\
\text { collection }\end{array}$ \\
$\begin{array}{l}\text { A global health instrument should be useable in self-administered surveys and applicable to telephone and face-to-face interviews, with } \\
\text { no intervention from the interviewer. It should be compatible with proxy responses, that is, responses given on behalf of the selected } \\
\text { respondent. The mode and proxy effects should be considered when designing the instrument and assessed during the test phase. }\end{array}$ \\
\hline
\end{tabular}

revealed that having a short set of questions was an effective way of increasing the acceptance of health questions into (non-) health surveys and censuses. Items from the MEHM were, for example, included into the Statistics on income and living conditions (EU-SILC), national surveys or censuses (eg, in France) and are going to be part of the future European Labour Force Survey. Global health measures are therefore good candidates for the calculation of internationally harmonised health expectancies.

To identify appropriate global heath instruments, we have specified four technical constraints that a good candidate should comply with: it should be concise but simple, usable for general population surveys and amenable to multimodes of collection (table 1). ${ }^{10-12}$

It is worth noting that global health instruments are usually not designed to capture health comprehensively. Global measures rather target separate health dimensions (eg, self-rated health, impairments, chronic conditions, activity limitations), which allows to calculate dimension-specific health expectancies (eg, life expectancy with some, severe or no activity limitation). In this respect, an approach based on global instruments differs from other summary measures of population health that combine multiple health dimensions, such as quality-adjusted life years (QALY) or health-adjusted life expectancies (HALEs). The later often use utility weights to combine wider set of items capturing multiple domains of health. ${ }^{13}$ Our approach also differs from the Global Burden of Disease (GBD) study which impedes regular monitoring and cross-country comparability by the amount of data required for the calculation of disability-adjusted life years or HALEs. For example, the latest HALEs of the GBD necessitate to estimate the prevalence of no less than 2337 sequelae of 301 diseases and injuries by age and sex, and for each country. ${ }^{14}$

In this paper, we argue that global survey instruments are the most suitable measures for regular and comparable monitoring of population health across multiple countries. When possible, however, they should be complemented with more specific instruments that can provide a greater depth of understanding through more detailed questions covering the health domains. ${ }^{4}$

\section{TWO DIMENSIONS OF HEALTH AS A MEASUREMENT PRIORITY}

There is no one single global measure of health but a range of measures that may tell (in)consistent stories about the health of the population as they may cover different dimensions. ${ }^{15}$ Among the many dimensions of health, disability, mental health and chronic morbidity receive a high level of consideration from (public) health researchers and practitioners surveyed by the JA-EHLEIS (see online supplementary file). We argue that disability is the key dimension for which a global measure is needed in order to obtain internationally comparable health expectancies. In fact, disability represents the consequence of injury and disease. As such it encompasses many other dimensions of health giving it an advantage over other more specific health dimensions such as chronic conditions or mental health.

Disability, like health, is a complex and multifaceted concept making comprehensive measurement with a global instrument difficult. ${ }^{1617}$ Of the different components of disability, participation restriction ${ }^{18}$ and functional limitation ${ }^{11} 1920$ were selected as the main goals for internationally harmonised global measures of health (box 1).

In the literature, attention has shifted from the medical model to the 'biopsychosocial' model of disability, which integrates environmental factors and puts the emphasis on participationthe ultimate step in the disablement process. ${ }^{21} 22$ Participation restriction accounts for: (1) the impact of the prevention, treatment and rehabilitation on impairment and functional limitations; and (2) the impact of actions aiming to increase the participation of people with functional limitations (accommodations and enabling environments). As measuring participation restriction alone does not enable one to differentiate these two impacts, a measure of functional limitation is also needed. Both dimensions are highly desirable owing to their policy relevance.

Disability policies from the United Nations and the EU emphasise the role of participation restriction and the necessity

\section{Box 1 Definitions of participation restriction and} functional limitation

Participation restriction-refers to limitation in the performance of roles and social involvement in activities such work and employment, school, leisure, parenting, housework, community, social and civic life. ${ }^{18}$ Participation gains its societal perspective by performance with or for others and is more influenced by environmental factors and social norms than other dimensions of disability.

Functional limitation-designates limitation in physical and mental actions. ${ }^{1120}$ Actions correspond to the category of 'willful actions' reflecting overall abilities of body and mind to carry out basic volitional bodily operations at the level of the organism (whole person): for example, walking, climbing steps, hearing, seeing, remembering. ${ }^{19}$ 
to have adequate measures for it. ${ }^{23} 24$ The United Nations Convention on the Rights of People with Disabilities defines persons with disabilities as "those who have long-term physical, mental, intellectual or sensory impairments which in interaction with various barriers may hinder their full and effective participation in society on an equal basis with others". 24

Ageing policies also acknowledge the importance of participation. Within the EU for instance, active and healthy ageing is seen as fundamental to the pursuit of smart, sustainable and inclusive growth and better jobs. ${ }^{25}$ The EU is accordingly monitoring the Healthy Life Years indicator, which is based on a global measure of participation restriction known as the GALI or Global Activity Limitation Indicator (box 2). ${ }^{46}$ In spite of its name, the GALI is considered as a measure of participation restriction rather than a measure of activity limitation because it implicitly refers to the ability for societal participation in a variety of settings (eg, employment/school, housework, leisure activities). ${ }^{21}$

Furthermore, the GALI and Healthy Life Years became the major health indicators within overall strategic policies of the EU, including the Lisbon strategy (2000-2010), the Europe 2020 strategy (2010-2020). This further evidences that participation restriction is highly relevant to various public policies.

Likewise, functional limitation has been shown to be a central component of health and disability policies. Recent international measures of functional limitation were developed by the Washington Group on Disability Statistics and the Budapest Initiative in order to specifically inform policies. Instruments were designed (1) to monitor the United Nations Convention on the Rights of Persons with Disabilities by identifying a population at risk for restrictions in ability to fully participate in society due to specific functional limitations in key domains; and (2) to provide internationally comparable health state statistics. ${ }^{27} 28$

\section{CHALLENGES AHEAD}

Agreement on the health dimensions to target for new internationally comparable health expectancies is a great step forward. Yet, major challenges are still ahead. They include the selection or design/adaptation of appropriate global survey measures, their adequate implementation into surveys, and ensuring cross-national comparability. We have sketched guidelines for future work and suggested how the international community could take our recommendations forward.

\section{Instruments selection or design}

In order to ease acceptability of the pursued disability measures, we have decided to rely as much as possible on existing work and available instruments. Our suggestion is twofold:

1. To develop a generic instrument of participation restriction using the European experience with the GALI development (box 2);

Box 2 The Global Activity Limitation Indicator (GALI) as used* in the European Union

For at least the past 6 months, to what extent have you been limited because of a health problem in activities people usually do? Would you say you have been...

severely limited

limited but not severely or

not limited at all?

*Statistics on income and living conditions (EU-SILC), European Health Interview Survey (EHIS).
2. To adopt the core items of the Washington Group short set instrument on disability to form a global measure of functional limitation and ensure the relevance of all its items for EU and OECD countries (box 3).

\section{Participation restriction}

A generally accepted global measure of participation restriction is currently missing. Whereas the European GALI is conceptually close to what is envisaged, ${ }^{15}{ }^{29-33}$ its lack of simplicity hampers its acceptability beyond the EU. Based on previous contributions, ${ }^{9} 101217$ we specified six conceptual characteristics of a desirable global measure of participation restriction (table 2): (1) comprehensive content of participation; (2) measure of participation performance with current accommodation; (3) health relatedness of the cause of participation restriction; (4) normative comparison in the level of participation; (5) long-term duration of restriction; (6) measure severity of restriction in the response scale (at least three levels).

The ideal measure should include all six conceptual characteristics while respecting the four technical constraints of global instruments defined in table 1 . In practice, a well-balanced instrument will have to slightly restrict its conceptual breadth in order to be concise and simple enough. To reach a well-balanced instrument, we suggest setting an unconditional constraint on simplicity, while optimising conciseness. Assessment of other technical constraints-usability for general population surveys and amenability to multimodes of collection-is less fundamental and can be carried out at a later stage.

To optimise conciseness, one should evaluate whether each conceptual characteristic should be explicitly included in the final instrument or left implicit (see possible implementations in table 2). Comprehensiveness of the measure of participation, health relatedness and normative comparison form the core of

Box 3 The four core questions of the Washington Group short set of questions on disability*

The next questions ask about difficulties you may have doing certain activities because of a health problem.

1. Do you have difficulty seeing, even if wearing glasses?
A. No-no difficulty
B. Yes-some difficulty
C. Yes-a lot of difficulty
D. Cannot do at all

2. Do you have difficulty hearing, even if using a hearing aid?
A. No-no difficulty
B. Yes-some difficulty
C. Yes-a lot of difficulty
D. Cannot do at all

3. Do you have difficulty walking or climbing steps?
A. No-no difficulty
B. Yes-some difficulty
C. Yes-a lot of difficulty
D. Cannot do at all

4. Do you have difficulty remembering or concentrating?

A. No-no difficulty

B. Yes-some difficulty

C. Yes-a lot of difficulty

D. Cannot do at all

*http://www.cdc.gov/nchs/data/washington_group/WG_Short_Measure_on_Disability.pdf 
Table 2 Conceptual characteristics of a desired global measure of participation restriction and possible implementations

\begin{tabular}{lll}
\hline Conceptual characteristic Description & Possible implementations
\end{tabular}

1. Comprehensive measures of participation restriction

2. Measure of performance with current accommodation

3. Cause of participation restriction: a health problem

4. Normative comparison in the level participation

5. Presence of long-standing restrictions

6. Severity of restrictions: inclusion of full range in the response with at least three levels
The instrument should cover numerous domains of participation such as work and employment, school, leisure, parenting, housework, community, social or civic life. It should account for the varying content of roles and forms of social involvement depending on birth cohort, age, gender, culture, period and place.

The instrument should measure performance as opposed to capacity, that is, what an individual does in his or her current environment. A measure of performance accounts for differences in the environment as a 'scene-setter' and informs on the extent to which an individual is adapted-with current accommodation - to his particular environment, and vice-versa. Performance encompasses the use of assistive devices and/or personal assistance as well as the built environment, attitudes towards persons with disabilities and laws on the rights of persons with disability.

The instrument aims to capture participation restrictions which have a health cause, as opposed to a socioeconomic cause, for example. It should cover all health-related reasons, including physical, mental and emotional health. Consequences of ageing should also be included as well as ill health caused by injuries/accidents, congenital conditions, birth defects, etc. It is irrelevant whether the health problem is diagnosed by a doctor or not. Knowledge about the specific health problem causing participation restriction is not sought. Following a normative model of disability, the instrument should assess respondents' level of participation against population standards or norms which are relative to cultural and social expectations. These norms vary by gender, age, culture or social status. An explicit reference to the norm enables to obtain a relative measure of disability (as opposed to an absolute measure) and to assess if people are well adapted to their environment. Such a measure can be comparable cross-culturally. In practice, the measure should include a comparison to peers or to the norm. Internal or habitual comparisons (eg, your usual activities) are not desirable.

The instrument should target long-standing restrictions. This allows to obtain more stable estimations of the prevalence of persons with disabilities and to exclude acute restrictions. Temporary, recurrent or seasonal restrictions are disregarded, which may in turn leave out the consequences of some mental health problems. A duration of at least 6 months is often used to define chronic or long-standing diseases in surveys. This period is also suggested to measure participation restriction.

Knowing the degree of severity (or difficulty) is desirable for reporting variations in population disability and testing hypotheses about population trends (eg, dynamic equilibrium hypothesis). A measure of severity with appropriate response options also makes an indicator more sensitive to change. Yet, measuring severity brings in additional cut-off points on the disability scale which may vary between cultures and population subgroups.
- Reference to multiple domains of societal involvement

- Reference to societal involvement in general, for example, 'activities'

- Question or clause on the use of assistive devices and/or personal assistance

- No reference to accommodation if respondents understand it that way, without a clause

General reference to health

- Reference to multiple health dimensions (to guide respondents' understanding of 'health')

- No reference to health problems if the survey context or preceding questions guide the interpretation of the question as health-related

Reference to what other people/peers do

- No reference to the norm if testing reveals that a clause does not enhance normative comparison

Question or clause on duration

No reference to long-standing restrictions if it can be shown that the respondent interpret a participation restriction as long-standing the instrument pursued. We therefore expect to find explicit reference to these characteristics in the final instrument, unless it has been proved that they can remain implicit without altering the conceptual breadth of the instrument.

At the end of the pretesting of different forms of the instrument, we expect several candidates to emerge with variable levels of conciseness and conceptual accuracy. A decision will have to be made regarding the balance between conceptual breadth and conciseness.

\section{Functional limitation}

From a conceptual perspective, our pursued global measure of functional limitation should be comprehensive; measure functioning 'within, on or near the skin" ${ }^{28}$; and assess the severity of the limitations.

The Washington Group on Disability Statistics recently suggested a short set of six items, each capturing a domain of functioning in a basic action or activity. The six domains are vision, hearing, mobility, communication, cognition/remembering and self-care. ${ }^{27}$ Our expert consultation and the experience of the Washington Group (which includes 133 members from National Statistical Offices, 7 international organisation members and 6 members from disabled persons organisations) both indicate that a generic global measure (ie, a one question instrument) of functional limitation is not feasible. Yet, as such, the Washington Group short set neither satisfies our criterion of parsimony (table 1), nor fully matches our definition of functional limitation (box 1). The proposal of the JA: EHLEIS is therefore to select four of the six Washington Group domains to form a global instrument (box 3). We excluded the item on self-care because it does not satisfy the 'within the skin' criterion. Self-care captures more complex activities (ie, washing all over or dressing) in which it is difficult to disentangle the impact of the environment. For parsimony purposes, we also decided not to keep the item on communication, which generally has a lower prevalence than the other four domains. Further 
discussion should however evaluate whether the four core domains selected (box 3) or other domains-such as pain, fatigue or affect-should be included in a final global instrument. Yet, given that the Washington Group short set is already widely used, is well accepted and was tested in various countries, strong arguments would be needed in order to include alternative domains of functioning in the global instrument.

By capturing four domains of functioning-vision, hearing, mobility and cognition/remembering-the proposed instrument (box 3) reaches a reasonable level of comprehensiveness at the cost of slight loss of conciseness (the other technical constraints (usability for general population surveys, simplicity and amenability to multimodes of collection) also being respected). The four items are structurally independent which means that the level of limitation in one of the four domains does not predetermine the level of limitation in any of the other domains. ${ }^{28}$ This property makes the global instrument of functional limitation compatible with the calculation of other summary measures of population health which rely on the use of valid preferencebased weights such as HALE or QALY. ${ }^{34}$

\section{Translation, testing, validation and implementation}

The newly created questions will need to be translated, tested (including cognitive interviews and focus groups involving the general population) and validated before implementation. Strict procedures have to be defined using best practice and existing protocols for translation, testing and validation. ${ }^{28}{ }^{35}{ }^{36} \mathrm{~A}$ higher level of comparability is better achieved if an instrument is implemented in similar ways across countries. ${ }^{30}$ Ideally, the data collection process of the two instruments should be identical in all countries and deviations from recommendations should be documented.

\section{Ensuring international comparability}

Cross-national comparability will have to be investigated. Like all reported data, global items are subject to cultural differences in reporting. Different reporting styles do not hamper crosscountry comparisons of trends, but they might be more problematic if one wants to compare or rank countries based on disability or health expectancy values. Comparability issues may involve both the understanding of underlying concepts and the use of the response scales.

Problems related to concepts should be minimised in the case of functional limitation, as indicated by the Washington Group rationale for measuring that specific dimension of disability. ${ }^{27}$ For participation restriction, the criterion of normative comparison has been proposed as a way of bypassing the problem. The criterion indicates that the global instrument should capture the extent to which individuals are restricted in their participation to the usual activities within a given environment. For example, it might be understood as going to the pub in England versus being involved in the local community in the USA. The fact that the meaning of (in)ability to participate varies by countries forms the basis of cross-country comparability. Such indicators provide relative as opposed to absolute measures of disability. ${ }^{37}$

As far as response scales are concerned, it is known that cut-off values of scales might have different meanings to different populations. The comparability of the response should therefore be carefully tested.

\section{Future international collaboration}

The series of seminars initiated by the JA: EHLEIS sets the basis for subsequent international collaboration, having as a core group Member States of the EU, the USA and Japan. Since the end of the JA: EHLEIS, national agencies from these countries have taken the recommendations forward and are pursuing the work. The involvement of national agencies (or international agencies in the case of the EU) is fundamental to the success of this initiative, as they ultimately decide to include or not to include survey items in their monitoring systems. The input from international organisations (such as WHO and OECD) should not be minimised, however, and the collaborations initiated by the JA: EHLEIS should be maintained and strengthened.

At the 2015 meeting of the Network on Health Expectancy and Disablement Process (REVES), the JA: EHLEIS initiative was positively received by (public) health researchers and professionals from around the globe, including developing countries. Given that the proposed blueprint is intended for EU and OECD members, the joining of low-income countries could bring additional challenges, such as the questioning of the relevance of the dimensions and items selected in a global context. The 2016 REVES meeting will take further the discussion.

\section{CONCLUSION}

Summary measures of population health-and health expectancies in particular-lack harmonisation outside the EU. In this paper, we put forward the development of two harmonised health expectancies to be based on two global measures of health: a global measure of participation restriction and a global measure of functional limitation.

The global measure of participation restriction, on the one hand, needs to be developed using the conceptual characteristics and guidelines sketched in this paper. The global measure of functional limitation, on the other hand, should use the questions developed by the Washington Group but needs further discussion on the number and selected core domains to be included.

This paper intends to serve as a blueprint for the actual development and implementation of the pursued indicators. Further work is therefore needed. Other countries, especially OECD members, are invited to join the initiative.

\section{What is already known on this subject}

- Summary measures of population health-in particular health expectancies - have become an essential tool for quantifying and monitoring population health.

- Current data do not allow meaningful comparisons at international level.

\section{What this study adds}

- We argue that harmonised health data needed for health expectancy calculation can best be obtained from 'global' survey measures, which provide a snapshot of the health situation using one or a few survey questions.

- Two global measures of health are pursued for their high policy relevance: a global measure of participation restriction and a global measure of functional limitation.

- We provide a blueprint for the future development and implementation of the two global measures. 
Acknowledgements This article summarises the report 'A blueprint for an internationally harmonised Summary Measure of Population Health' produced by the Joint Action EHLEIS. ${ }^{7}$

Contributors HVO initiated the study and overall design. NB wrote the first draft. NB and HVO redrafted the manuscript. J-MR, TO and JM critically reviewed the manuscript. All authors read and approved the final manuscript.

Competing interests None declared.

Provenance and peer review Not commissioned; externally peer reviewed.

Open Access This is an Open Access article distributed in accordance with the Creative Commons Attribution Non Commercial (CC BY-NC 4.0) license, which permits others to distribute, remix, adapt, build upon this work non-commercially, and license their derivative works on different terms, provided the original work is properly cited and the use is non-commercial. See: http://creativecommons.org/ licenses/by-nc/4.0/

\section{REFERENCES}

1 Murray CJ, Salomon JA, Mathers CD, et al. Summary measures of population health: concepts, ethics, measurement and applications. World Health Organization, 2002.

2 Stiefel MC, Perla RJ, Zell BL. A healthy bottom line: healthy life expectancy as an outcome measure for health improvement efforts. Milbank Q 2010;88:30-53.

3 Robine JM. Summarizing health status. In: Pencheon D, Guest C, Melzer D, Gray M, eds. Oxford handbook of public health practice. 2nd ed. Oxford Oxford University Press, 2006:160-68.

4 Robine JM, Jagger C, Egidi V, et al. Creating a coherent set of indicators to monitor health across Europe: the Euro-REVES 2 project. Eur J Public Health 2003;13:6-14.

5 Healthy People 2020. General Health Status. 2011. http://healthypeople.gov/2020/ about/GenHealthAbout.aspx\#healthy (accessed 19 Feb 2016).

6 Brønnum-Hansen $\mathrm{H}$. Ranking health between countries in international comparisons. Scand J Public Health 2014:42:242-4.

7 Berger N, Van Oyen H, EHLEIS team. WP7: A blueprint for an internationally harmonised Summary Measure of Population Health. JA:EHLEIS Technical Report 2014_7.5. 2014. http://www.eurohex.eu/pdf/Reports_2014/2014_TR7204_ A20blueprint.pdf (accessed 19 Feb 2016)

8 Robine JM, Cambois E, Nusselder W, et al. The joint action on healthy life years (JA: EHLEIS). Arch Public Health 2013;71:2.

9 Verbrugge LM, van den Bos GAM, Van de Water H. A REVES enterprise: developing a global disability indicator. REVES paper 1996(280).

10 Perenboom R, Van Oyen $\mathrm{H}$, van Herten L. Limitations in usual activities, a global approach. In: Robine JM, Jagger C, Romieu I, eds. Selection of a coherent set of health indicators for the European Union. Montpellier: Euro-Reves, 2002:67-80.

11 Verbrugge LM, Jette AM. The disablement process. Soc Sci Med 1994;38:1-14.

12 Verbrugge LM, Merrill SS, Liu X. Measuring disability with parsimony. Disabil Rehabil 1999;21:295-306.

13 Wolfson MC. Health-adjusted life expectancy. Health Rep 1996;8:41-6; (Eng); 439 (Fre).

14 Murray CJ, Barber R, Foreman K, et al., GBD 2013 DALYs and HALE Collaborators. Global, regional, and national disability-adjusted life years (DALYs) for 306 diseases and injuries and healthy life expectancy (HALE) for 188 countries, 1990-2013: quantifying the epidemiological transition. Lancet 2015;386:2145-91.

15 Cabrero-García J, Juliá-Sanchis R. The Global Activity Limitation Index mainly measured functional disability, whereas self-rated health measured physical morbidity. J Clin Epidemiol 2014;67:468-76.

16 Mont D. Measuring health and disability. Lancet 2007:369:1658-63.

17 Verbrugge LM. A global disability indicator. J Aging Stud 1997;11:337-62.
18 Dijkers MP. Issues in the conceptualization and measurement of participation: an overview. Arch Phys Med Rehabil 2010;91:S5-16.

19 Madans JH, Altman BM, Rasch EK, et al. Washington Group Position Paper: Proposed Purpose of an Internationally Comparable General Disability Measure. 2004. http://www.cdc.gov/nchs/data/washington_group/WG_purpose_paper.pdf (accessed 19 Feb 2016).

20 Nagi SZ. The concept and measurement of disability. In: Berkowitz ED, ed. Disability, policies and government programs. New York: Praeger, 1979:1-15.

21 WHO. International Classification of Functioning, Disability and Health: ICF. 2001. http://www.who.int/classifications/icf/en/ (accessed 19 Feb 2016).

22 WHO. Towards a common language for functioning, disability and health: ICF. 2002. http://www.who.int/classifications/icf/training/icfbeginnersguide.pdf (accessed 19 Feb 2016)

23 Leonardi M. Measuring health and disability: supporting policy development. The European MHADIE project. Disabil Rehabil 2010;32(Suppl 1):1-8.

24 UN General Assembly. Convention on the Rights of Persons with Disabilities: resolution/adopted by the General Assembly. UN General Assembly, 2007.

25 Lagiewka K. European innovation partnership on active and healthy ageing: what have been the policy drivers and determinants to set a headline target of 2 additional Healthy Life Years at birth at EU average by 2020. Arch Public Health 2012:70:23.

26 Van Oyen $\mathrm{H}$, Van der Heyden J, Perenboom R, et al. Monitoring population disability: evaluation of a new Global Activity Limitation Indicator (GALI). Soz Praventiv Med 2006;51:153-61.

27 Madans JH, Loeb ME, Altman BM. Measuring disability and monitoring the UN Convention on the Rights of Persons with Disabilities: the work of the Washington Group on Disability Statistics. BMC Public Health 2011;11(Suppl 4):S4.

28 United Nations Economic Commission for Europe. Survey Module for Measuring Health State. Developed by the Budapest Initiative Task Force on Measurement of Health Status. 2013. http://www.unece.org/fileadmin/DAM/stats/publications/BI Report_to_CES_2012_-_BI-M2_Final_Version_10_with_cover.pdf (accessed 19 Feb 2016).

29 Berger $\mathrm{N}$, Van der Heyden J, Van Oyen $\mathrm{H}$. The global activity limitation indicator and self-rated health: two complementary predictors of mortality. Arch Public Health 2015;73:1-7.

30 Berger N, Van Oyen H, Cambois E, et al. Assessing the validity of the Global Activity Limitation Indicator in fourteen European countries. BMC Med Res Methodol 2015;15:1-8.

31 Jagger C, Gillies C, Cambois E, et al. The Global Activity Limitation Index measured function and disability similarly across European countries. J Clin Epidemiol 2010;63:892-9.

32 Van der Heyden J, Van Oyen H, Berger N, et al. Activity limitations predict health care expenditures in the general population in Belgium. BMC Public Health 2015;15:1-12.

33 Verropoulou G. Specific versus general self-reported health indicators predicting mortality among older adults in Europe: disparities by gender employing SHARE longitudinal data. Int J Public Health 2014;59:665-78.

34 Furlong WJ, Feeny DH, Torrance GW, et al. The Health Utilities Index (HUI) system for assessing health-related quality of life in clinical studies. Ann Med 2001:33:375-84

35 Alcser K, Benson G, Börsch-Supan A, et al. The Survey of Health, Aging, and Retirement in Europe-Methodology. 2005. http://www.share-project.org/uploads/ tx_sharepublications/SHARE_BOOK_METHODOLOGY_Wave1.pdf (accessed 19 Feb 2016).

36 European Social Survey. ESS Methodology Overview. 2016. http://www. europeansocialsurvey.org/methodology/ (accessed 19 Feb 2016).

37 Ziebland S, Fitzpatrick R, Jenkinson C. Tacit models of disability underlying health status instruments. Soc Sci Med 1993;37:69-75. 